\title{
SOBRE DIBUJO \\ E HISTORIA DE LA ARQUITECTURA Entrevista con Rafael Manzano Martos
}

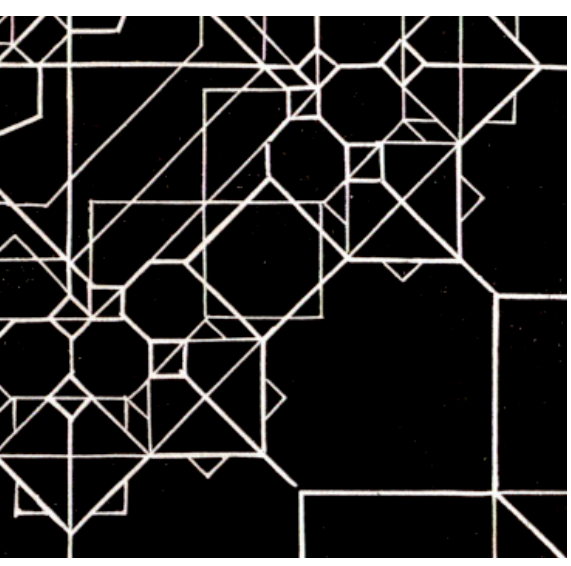

\section{Antonio Gámiz Gordo}

Upon the drawing and history of architecture. Interview with Rafael Manzano Martos

Boletín Académico. Revista de investigación y arquitectura contemporánea

Escuela Técnica Superior de Arquitectura. Universidade da Coruña

elSSN 2173-6723

unw.boletinacademico.com

Número 3 (2013)

Páginas 65-72

Fecha de recepción 29.10.2012

Fecha de aceptación 22.01.2013

https://doi.org/10.17979/bac.2013.3.0.998

\section{Resumen}

A partir de cuatro preguntas, Rafael Manzano Martos reflexiona sobre la gran importancia del dibujo en la producción arquitectónica, con referencias a planos y maquetas de notables obras en la historia de la arquitectura. Se apuntan razones sobre la escasez de dibujos originales hoy conservados, que en todo caso estarían más cercanos al mundo de la técnica -una técnica artística muy elemental-, que al mundo del arte o la poesía. Y se valora la aparición de la perspectiva en el Renacimiento como instrumento trascendental para el desarrollo de la visión espacial, el dominio del espacio y la creación arquitectónica.

\section{Abstract}

On the basis of four questions, Rafael Manzano Martos reflects upon the importance of drawing in the architectonic creation, with references to plans and models of masterpieces in the history of architecture. Some reasons about the lack of original drawings preserved nowadays are pointed out; drawings that, in any case, are closer to the field of technique - a very elemental artistic technique- than to the field of art or poetry. The introduction of perspective in the Renaissance period as a crucial element in the development of the spatial vision, and the mastery of space and architectonic creation are also appraised.

\section{Palabras clave}

Dibujo, Historia, Arquitectura, Maqueta, Perspectiva

\section{Keywords}

Drawing, History, Architecture, Model, Perspective 


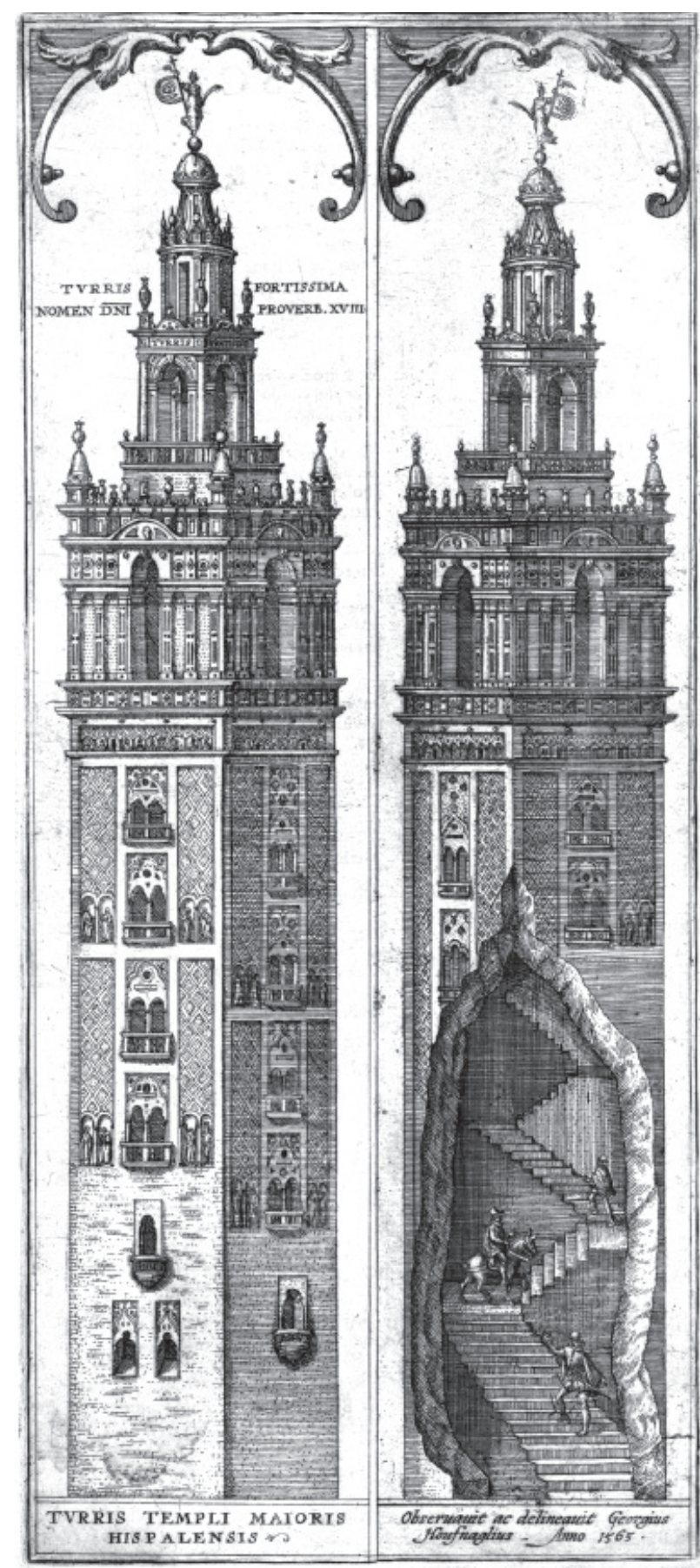

1 Joris Hoefnagel, vistas de la Giralda de Sevilla, 1565
Rafael Manzano Martos nació en Cádiz en 1936. Se tituló como arquitecto en 1961 en la Escuela Técnica Superior de Arquitectura de Madrid, donde impartió docencia hasta 1966, cuando obtuvo la Cátedra de Historia del Arte y la Arquitectura en la Escuela Técnica Superior de Arquitectura de Sevilla. Desde entonces ha ejercido su docencia más de cuarenta años en dicha Escuela, de la que fue Director-Decano entre 1974 y 1978.

Es miembro de la Real Academia de Bellas Artes de San Fernando de Madrid y de otras Reales Academias. Ha impartido incontables conferencias, y cuenta con abundantes publicaciones sobre historia de la arquitectura, arte y urbanismo. Además ha restaurado numerosos monumentos por toda España.

Entre sus galardones destacan la Medalla de Oro de las Bellas Artes Españolas y el prestigioso premio Richard H. Driehaus 2010, otorgado en Chicago por la Universidad de Notre Dame (Indiana, EEUU), que fomenta la arquitectura clásica y el urbanismo tradicional.

Rafael Manzano ha fundamentado su trayectoria profesional y docente en un profundo conocimiento de la historia de la arquitectura y en un uso hábil e inteligente del dibujo, cuestiones que centran la presente entrevista.

En este sentido, las intenciones u objetivos del presente texto se enmarcan en el interés por explorar territorios comunes de investigación entre dos áreas de conocimiento a las que pertenecen entrevistado y entrevistador: Historia de la Arquitectura y Expresión Gráfica Arquitectónica. Para ello se articulan cuatro apartados con preguntas y respuestas transcritas a continuación.

\section{SOBRE DIBUJO Y ARQUITECTURA}

¿Cree que el uso del dibujo ha influido de forma determinante en la producción arquitectónica a lo largo de la historia?

Es evidente que el dibujo ha sido un elemento fundamental en el desarrollo de la producción arquitectónica a lo largo de la historia. Pienso que no hay otra forma de expresar primariamente la idea arquitectónica, de plasmarla, de poderla ejecutar, si no es a través de una serie de dibujos, tanto de las formas generales y replanteo del edificio, como de los detalles arquitectónicos de cada uno de sus elementos orgánicos. 
Hubo una época en la cual la idea arquitectónica se plasmaba escultóricamente en una maqueta o modelo: sabemos que había modelos arquitectónicos, más o menos, de todas las grandes obras de arquitectura del Renacimiento, completos o parciales ${ }^{1}$. Por ejemplo, del palacio de Carlos V había una cuarta parte del patio como modelo. También hubo modelos que a su vez fueron dibujados; por ejemplo, el de la Giralda de Hernán Ruiz, que aparece en el Civitatis Orbis Terrarum (Fig. 01), no pudo ser dibujado del propio edificio de la Giralda, que estaba en ese momento envuelto por el proceso constructivo del cuerpo de campanas. El dibujo no es el de una torre real, es el dibujo de una maqueta o modelo. Y algo de esto pasa con algún otro edificio, por ejemplo con la sección de Heylan de la cabecera de la Catedral de Granada, de Siloé (Fig. 02): también se ve muy claramente que es el dibujo de una maqueta. Por lo tanto hasta conocemos modelos a través de dibujos de modelos.

Pero aparte de eso, para poder hacer o fabricar esos modelos era preciso que se dibujaran previamente, y que el modelista, luego, los ejecutase. O sea, que el proceso de plasmar en un modelo lo que se ha trabajado primero como dibujo arquitectónico es un paso adelante, un paso intermedio entre el proceso creativo de la arquitectura y la ejecución definitiva de la misma.

\section{SOBRE DIBUJO Y CONTEXTO HISTÓRICO}

Apenas se conocen dibujos o planos originales en determinados periodos históricos, de ciertas culturas o tipos de arquitectura — por ejemplo sobre la arquitectura islámica-, a pesar de la indudable calidad de muchos de sus edificios. ¿A qué cree que puede deberse?

Bueno, yo creo que fundamentalmente se debe a dos motivos. Uno, a que se le ha dado poca importancia, una vez construido el edificio, a la conservación de esos planos o dibujos y se han perdido en el tiempo, se han dispersado, se han destruido en muchos casos. Otras veces puede haber ocurrido lo contrario: un afán coleccionista de ese tipo de dibujos que ha llevado a que se congregasen en determinadas piñas coleccionisticas, como ocurrió en el caso de Felipe II. Éste se llevó de distintas catedrales - como la de Sevilla o la de Toledo- sus planos becerros, sus planos de obra, que él coleccionaba, y reunió muchos de ellos en una de las torres del Alcázar de Madrid, donde tenía su gran colección de planos, dibujos arquitectónicos y modelos de madera, que debió ser una de las mejores del mundo. Todo se perdió en el incendio del Alcázar de Madrid en la Nochebuena de 1734. Y de este modo desapareció de golpe la colección gráfica más rica de la arquitectura española. O sea, que tanto la pérdida de interés como el excesivo interés por agrupar dibujos puede ser causa de su destrucción.

Tenemos alusiones a dibujos arquitectónicos del periodo concreto que citas, el Islam. En documentos nazaríes estudiados por una arabista que conozco, Alicia de la Higuera, conservados en Fez —en palacios de familias descendientes de los nobles allí refugiados tras la conquista de Granada-, se habla de que el sultán Muhammad V era el arquitecto tanto del patio de los Leones como de los Alijares, y todo se hacía de acuerdo con ideas y dibujos que él facilitaba. Luego este sultán dibujaba como un arquitecto ${ }^{2}$.

Ella vino a contarme esto porque quería saber cómo había documentado yo un capítulo de mi libro sobre la Alhambra titulado «Muhammad V, el sultán arquitecto ${ }^{3}$. Yo le dije que las obras de arquitectura acometidas en su reinado sólo las pudo crear él, porque era el único, presuntamente, que había visto los modelos de donde proceden. Yo le decía que la Alhambra de Muhammad V es como la Acrópolis de Atenas: es una recreación de una serie de episodios arquitectónicos muy antiguos, muchos ya en desuso, ya caídos, olvidados, o en recesión, que seguramente los artistas de la Acrópolis fueron a visitar, movidos por Pericles, para crear allí una síntesis de la arquitectura de todas las Grecias. Vieron una serie de cosas que ahora, evidentemente, se renuevan para crear una nueva sugestión arquitectónica muy distinta, muy superior y mucho más importante que la que le había dado origen. Por eso decía yo que a Muhammad V en su exilio - seguramente en su tristeza de exiliado-, le interesó la arquitectura, vio muchas cosas que luego recreó en su obra posterior, como por ejemplo el «chafariz de peregrina forma» —según el texto de Ibn al Jatib [año 1362] — del patio que hoy llamamos de Machuca, del Mexuar de la Alhambra, que es copia de una fuente romana, de un impluvium de Volúbilis. Eso lo vio Muhammad $V$ en su exilio, al igual que contempló las bóvedas estalactíticas de la Qarawiyyin de Fez, realizadas en época almorávide por artistas hispanos, que son obras fantásticas. Y envió allí, sin duda, a gente que las dibujó, para acometer las bóvedas de mocárabes de las salas de Dos Hermanas o Abencerrajes de la Alhambra a partir de estas bóvedas magrebíes, interpretándolas con cambios y mutaciones nuevas, para lo cual hubo que dibujarlas. Es un problema de trazado complejísimo (Fig. 03). Y las armaduras mudéjares también hay 


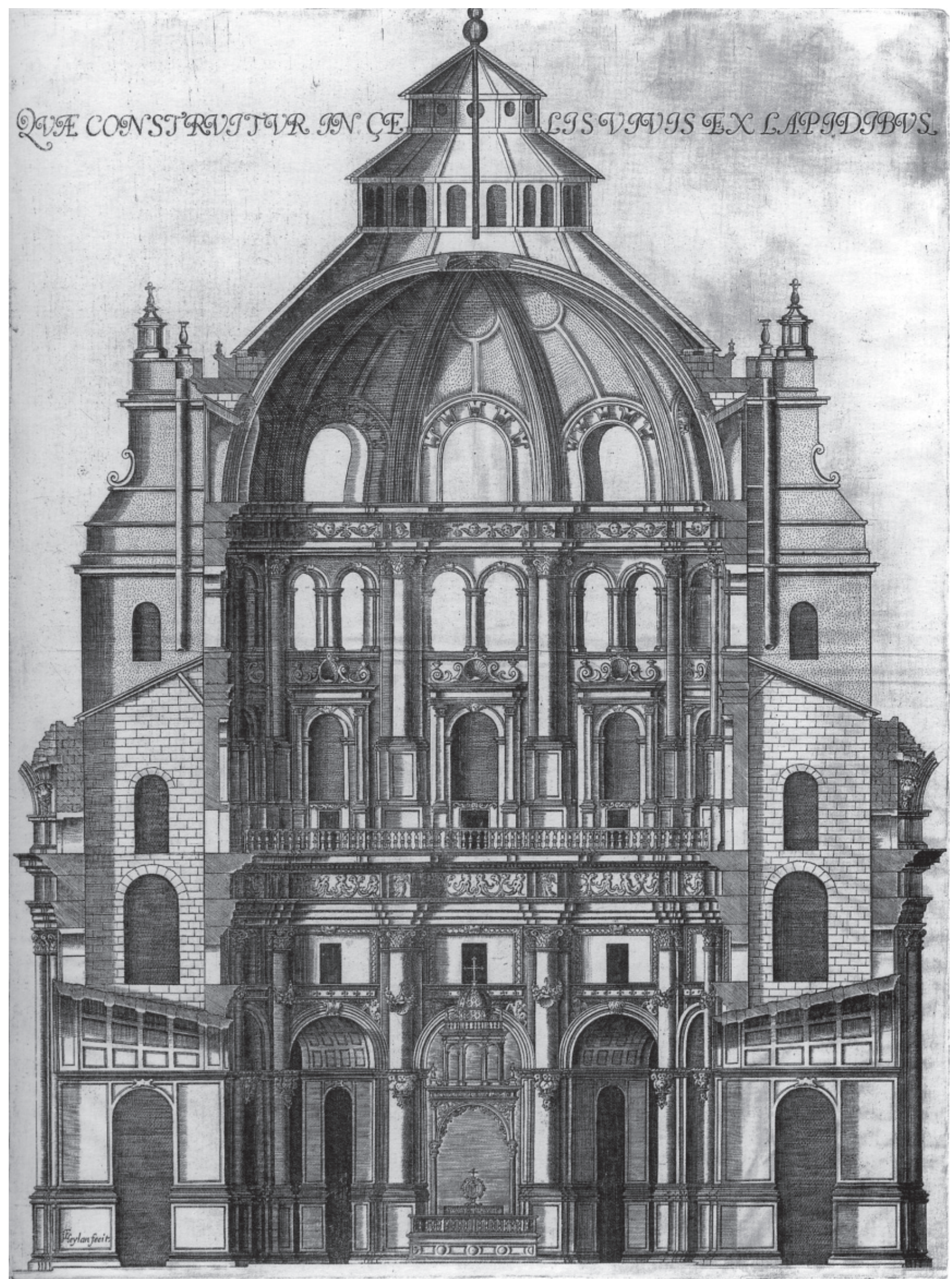

2 Francisco Heylan, sección de la Capilla Mayor de la Catedral de Granada, h. 1620 
que dibujarlas, con un sistema de plantillas o como quieras... Todo hay que dibujarlo, antes de convertirlo en arquitectura.

\section{SOBRE LA DISCIPLINA GRÁFICA Y ARQUITECTÓNICA}

¿Considera que el dibujo de arquitectura, a lo largo de la historia, se encuentra más cercano al mundo de la técnica $o$ al del arte y la poesía?

Pues yo creo que se aproxima más a la técnica - a una elemental técnica artística por supuesto- que a la poesía. Yo creo que la poesía es una cosa que intentan extraer de la arquitectura los que la contemplan como historiadores, como poetas, como personas que aman aquello y que encuentran allí una poética. La obra arquitectónica tiene, evidentemente, su propia poética en cada época, en sus problemas, en toda su historia... Toda obra tiene una capacidad de evocación que genera una poética de su contemplación.

Pero yo creo que en la construcción de la obra arquitectónica el arquitecto no es un poeta: es un técnico o un artista, o un técnico-artista, como quieras llamarlo. Pero también es un artesano, una mezcla de artista y de técnico modesto, porque la arquitectura no ha tenido nunca una tecnología altísima...

Yo creo que el arquitecto es un técnico derivado de su experiencia, un técnico empírico, que en algún momento dado - quizás en un arranque poéticoha querido explorar las posibilidades máximas de las estructuras.

Estoy pensando en el artista que hizo la cabecera gótica de la catedral de Beauvais, y estoy casi seguro de que este artista quiso alcanzar lo inalcanzable - y en eso falló, porque todas las cosas tienen su tensión máxima- y superados los puntos críticos, se le hundió parcialmente y hubo que acometer modificaciones, duplicar el número de apoyos, etc., para hacer viable una catedral de cuarenta y ocho metros de altura hasta la clave de sus bóvedas (Fig. 04). De todas formas, pienso que incluso de la reconstrucción de Beauvais -que no responde a su idea primitiva — surgió alguna virtud, porque el módulo tan estrecho y tan alto contribuyó a hacer más visible aún ese deseo del artista de llegar a la máxima elevación, a la máxima verticalidad del edificio, que por otro lado es una de las virtudes y de los elementos emblemáticos del gótico en aquellas tierras ${ }^{4}$.
El gótico francés suspiró por alcanzar las máximas alturas, como el gótico inglés suspiró por las profundidades, por iglesias telescópicas, largas, que han ido creciendo a lo largo de la historia. Y las catedrales del gótico español se desarrollaron en anchura - forzadas por los solares de las antiguas mezquitas - en casos como la de Sevilla, sin la longitud o elevación que hubiera tenido una catedral de ese porte en el gótico inglés o francés.

Por otra parte, el dibujo también puede ser una forma de expresar poéticamente la belleza de la arquitectura. De hecho, yo pienso que los dibujantes y grabadores del siglo XIX llamados románticos, fueron poetas en la interpretación plástica, dibujística, pictórica, de las obras de arquitectura que intentaban plasmar ${ }^{5}$. Las describen desde una imagen que tiene mucho de literario, mucho de una época, de un ambiente: el de la España no industrializada y felizmente virgen, cuando ya toda Europa había perdido su virginidad en la revolución industrial. España se presentaba, entre otras cosas, con una vena de orientalismo que estaba muy presente en la lírica del momento. Entonces, si comparamos las lecturas de Chateaubriand, de Gautier o de los literatos románticos que visitaron España en aquel tiempo, con las imágenes de litógrafos de entonces, vemos que el grabado o la litografía son la mejor ilustración de sus poéticas descripciones.

\section{SOBRE VISIÓN ESPACIAL Y PERSPECTIVA}

¿Que cuestiones gráficas, teorías o autores considera de especial importancia para el desarrollo de la visión espacial o el control formal del espacio arquitectónico a lo largo de la historia?

Aquí hay un tema clásico, la perspectiva en el Renacimiento: hasta entonces los antiguos no habían conocido - ni en la Edad Media se habían llegado a conocer- las reglas de la perspectiva lineal o cónica. Intuitivamente, Giotto por ejemplo, con un cierto naturalismo, intentaba dimensionar las figuras en su proporción correlativa a la lejanía en la que estaban situadas. Era un intento de estudiar la naturaleza a través del ojo humano, pero no se conocían las reglas ${ }^{6}$.

Cuando se descubren dichas reglas aparece algo que fue tan importante para la historia de la arquitectura como el descubrimiento de América para la historia de los descubrimientos, que significa el conocimiento del mundo como esfera, su dominio por el hombre. No se puede dominar lo que no 

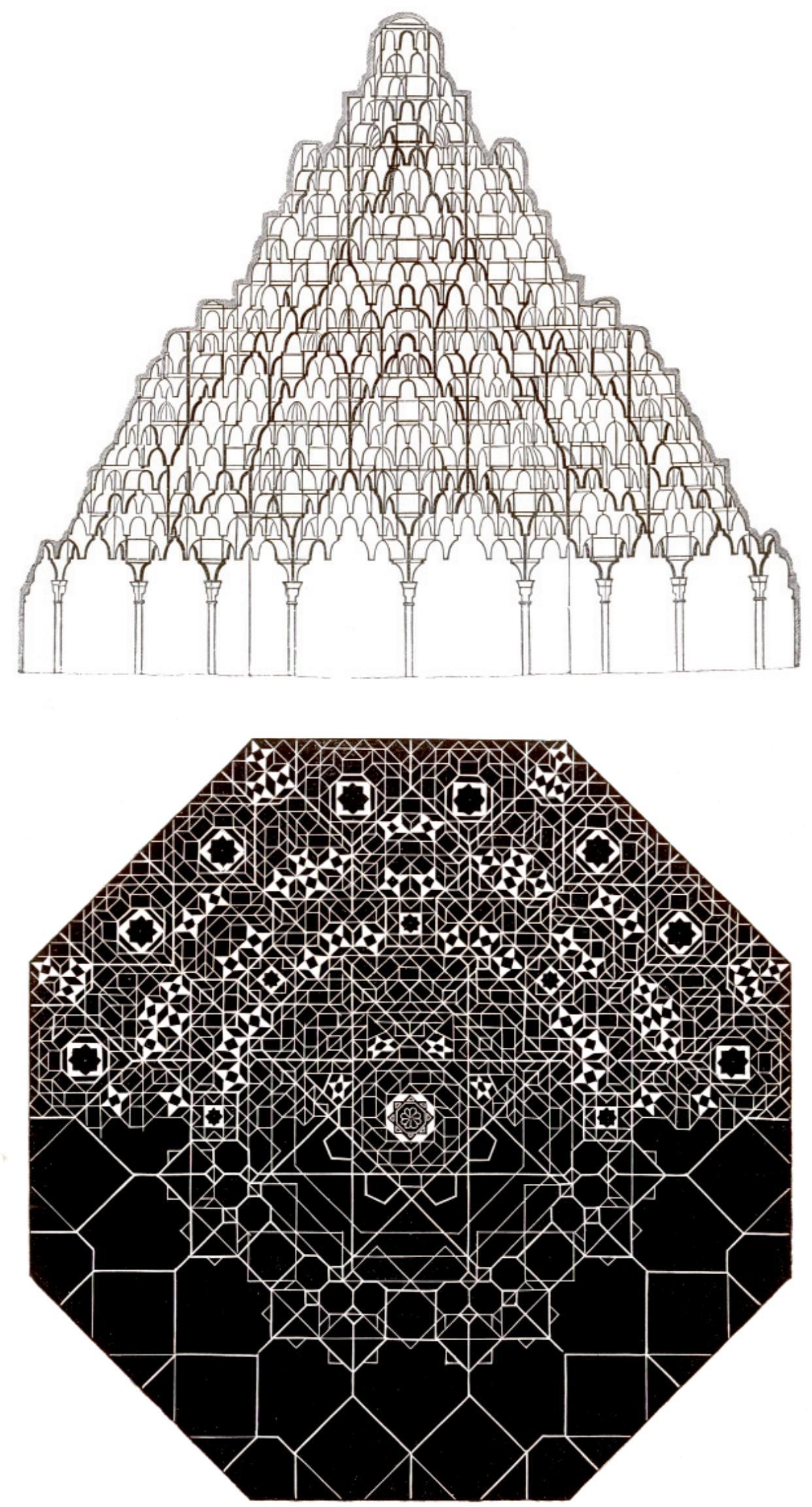

3 Owen Jones, planta y sección de la bóveda de mocárabes en la Sala de las Dos Hermanas de la Alhambra, 1842 
se conoce. La perspectiva significa el dominio del espacio ficticio, que es la representación sobre un plano de lo que estamos viendo, de lo que queremos imaginar o queremos construir y convertir en espacio arquitectónico. El dominio del espacio es darle a cada punto su posición exacta, y la dimensión de un objeto en ese espacio perfectamente dominado y dibujado por la perspectiva. Por lo tanto, el control perspéctico del espacio, dibujado sobre un plano, nos da el dominio perfecto de la proyección previa que el arquitecto hace de su arquitectura.

Cuando los arquitectos dibujamos o proyectamos, estamos imaginando en perspectiva, y a veces lo expresamos con perspectivas más o menos detalladas. Bueno, ya no dibujamos perspectivas perfectas a mano porque usamos el ordenador y están los $3 D$ que han venido a sustituir, con muchas ventajas y mucha comodidad -aunque con menos arte y con menos gracia- el dibujo en perspectiva que el arquitecto hacía para expresar su proyecto y facilitar la interpretación de sus dibujos en diédrico.

La verdad es que las proyecciones diédricas y perspécticas significan el dominio del espacio, y esto es lo que hicieron los grandes arquitectos del primer Renacimiento, junto con los pintores. Como ejemplos podemos recordar la Santísima Trinidad de Masaccio en Santa María Novella de Florencia, o el coro ilusionistico de Bramante en Santa María presso San Sátiro, en Milán (Fig. 05), que es una obra maestra de la invención del espacio puramente teórico, o como se dice hoy, del espacio virtual.

O sea, lo mismo que ahora se hacen espacios virtuales con el ordenador, puede vivirse virtualmente un proyecto arquitectónico, y podemos recorrerlo internamente estudiando sus espacios en tres dimensiones, entonces se usaron las reglas de la perspectiva para crear espacios ficticios, mágicos.

Esto ocurre en otras muchas obras de arquitectura, en las cuales Bramante o los primeros arquitectos del Renacimiento usaron la perspectiva y creyeron en ella como una teoría bellísima. Pero en realidad no era una teoría, era una práctica, una forma de expresar pictóricamente el espacio arquitectónico, una pura operación descriptiva que servía instrumentalmente para la creación de aquellos arquitectos. De este modo, el dibujo y la perspectiva — como invento de conocimiento geométrico- ayudaron muchísimo a la invención formal de la arquitectura renacentista.
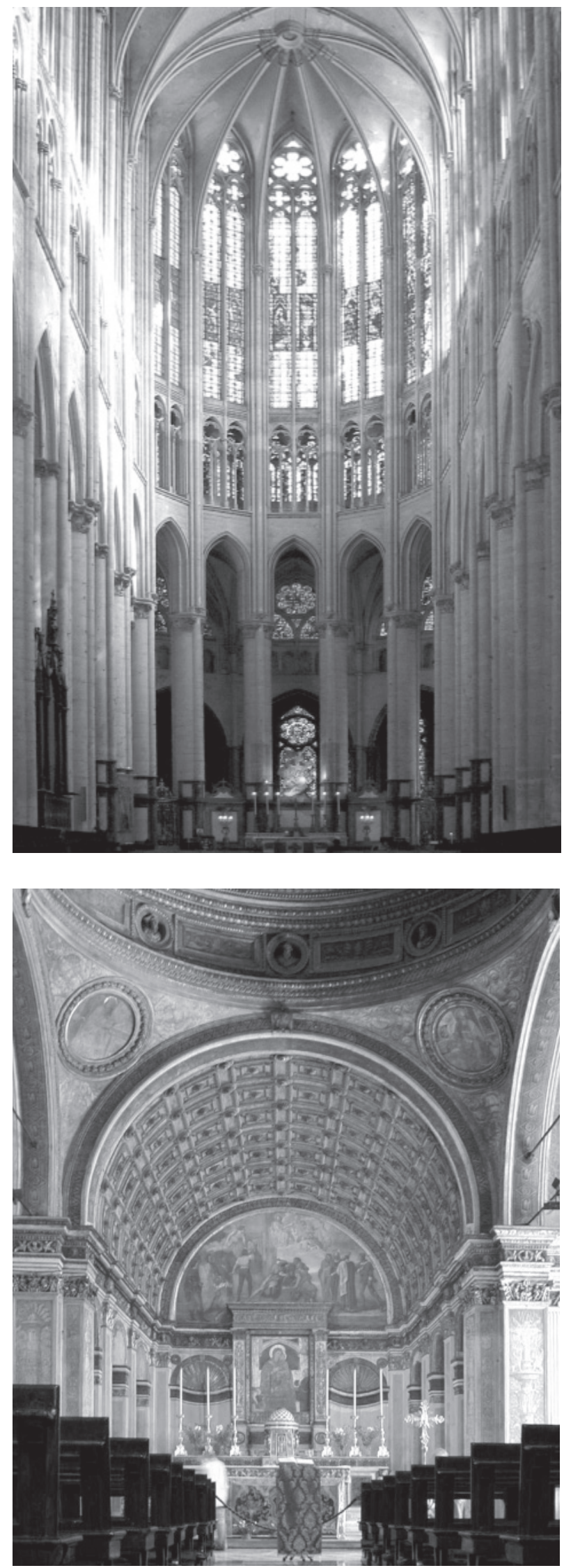

4 Foto actual de la cabecera gótica reconstruida de la catedral de Saint-Pierre de Beauvais, Oise, Picardie (Francia), h. 1272/84

5 Foto actual del coro ilusionístico de la iglesia de Santa María presso San Sátiro, Milán; Donato Bramante, h. 1482/86 


\section{REFLEXIÓN FINAL}

A modo de conclusión, ante el actual panorama de incertidumbres sobre el sentido de la profesión de la arquitectura, las palabras de Rafael Manzano invitan a plantear renovadas investigaciones sobre el quehacer del arquitecto a lo largo de la historia. Queda claro que el dibujo constituye una clara seña de identidad de nuestra profesión, y que está íntimamente ligado a muy diversas ideas arquitectónicas en muy distintos tiempos o contextos culturales.

Además, todo ello hace pensar en la necesidad de nuevas investigaciones con miradas entrecruzadas entre áreas de conocimiento o disciplinas que a lo largo de la historia han confluido - y hoy siguen confluyendoen la complejidad de la arquitectura, su docencia y su ejercicio profesional.

\section{Notas}

1. Cf. Varios autores, Rinascimento. Da Brunelleschi a Michelangelo. La rappresentazione dell'Architectura (catálogo de la exposición) (Milán: Bompiani, 1994).

2. Cf. Alicia de la Higuera y Antonio Morales Delgado, «La almunia de los Alijares según dos autores árabes: Ibn Asim e Ibn Zamrak», Cuadernos de la Alhambra 35 (1999): 31-48.

3. Rafael Manzano Martos, La Alhambra. El universo mágico de la Granada islámica (Madrid: Anaya 1992).

4. Cf. Varios autores, El gótico. Arquitectura, Escultura, Pintura (Colonia: Könemann, 1999).

5. Cf. Varios autores, La imagen romántica de España (catálogo de la exposición) (Madrid: Ministerio de Cultura, 1981).

6. Cf. José María Gentil Baldrich, Sobre la supuesta perspectiva antigua (y algunas consideraciones modernas) (Sevilla: Universidad de Sevilla, 2011).

\section{Procedencia de las Ilustraciones}

Fig. 01-02. Colección particular de Rafael Manzano Martos.

Fig. 03. Colección particular de Eduardo Páez López.

Fig. 04-05. Archivo fotográfico del autor de la entrevista.

\section{Sobre el autor}

Antonio Gámiz Gordo. Doctor Arquitecto. Profesor Titular del Departamento de Expresión Gráfica Arquitectónica de la Escuela Técnica Superior de Arquitectura de Sevilla

antoniogg@us.es 